\section{EDITORIAL COMMENTS}

The Health Department, with other health authorities and water supply agencies, has recognised the potential importance of protozoan parasites in drinking water supplies and their possible role in previously unexplained outbreaks of gastroenteritis.

Mr Archer raises the issue whether Cryptosporidium should be monitored routinely. The key issue, however, is the role of indicators and the way this information is used in managing water supplies. Knowledge of the environmental conditions in the drinking water catchments is critical. The Department strongly supports the principle of multiple barriers based first on raw water of the highest possible quality. Indicators then are used for quality control and, where necessary, additional indicators can be used to test for probable contamination based on knowledge of the catchments. It is not necessary to test for all the individual contaminants of concern.

The Canadian water supply referred to by $\mathrm{Mr}$ Archer was known to be contaminated with human sewage. This raises a number of questions:

- Were the treatment processes provided appropriate given this source of contamination?

Did the indicators used provide assurance of process control and, therefore, water quality?

What were the environmental and recreational impacts to the waterways and the consequences for all users of the water?

These questions need a broad, strategic answer and cannot be avoided by a different monitoring regime. In assessing the implications of the new water plants the Water Board has made such a holistic commitment to managing Sydney's water supply. As well as upgrading the water treatment processes, the Water Board has a concurrence role over development in the "inner catchments"; it is promoting catchment management of privately owned land and is eliminating or upgrading sewage effluent disposal within the catchments.

Based on information provided by the Water Board the Department does not believe the levels of Cryptosporidium found in Sydney's water supply in June 1993 represented a public health threat. Mr Archer is quite right, however, when he states that we really do not know the infective dose for Cryptosporidium. It is considered to be quite low maybe 10 oocysts or fewer, and possibly as low as 1 oocyst per person. Certainly the dose will vary for individuals and is most critical for immunologically impaired groups. The absence of a specific action level for Cryptosporidium in the most recent (draft) NHMRC Guidelines for Drinking Water is a reflection of this uncertainty. An animal model has recently been developed which may provide more information on the behaviour of the organism.

The Health Department is developing a more clearly defined audit role for drinking water quality as a result of the proposed corporatisation of the Water Board. Any agreement will address all issues of water quality, including raw water supplies, quality assurance/quality control and the most appropriate indicators for routine and event monitoring.

\section{PUBlic HEALTH ABSTRACTS} School of Health Service Management at the University of NSW, has prepared the following public health items from the literature.

\section{HIGH RATES OF DISABILITY IN IMMATURE INFANTS}

Neo-natal intensive care has been described as 'perhaps the most successful of all medical technologies'. In terms of improving the chance of survival this may be so, but the rate of disabilities among the survivors is high as has been shown by a comprehensive survey involving nearly 100,000 infants in the United Kingdom. About 3.5 of 1,000 of these births were before 29 weeks of gestation. Half the babies survived to be discharged from the nursery. At four years, 93 per cent of the premature infants were still alive. Only 35 per cent of those four-year-olds were within normal limits. Around 29 per cent had mild disability, 13 per cent a moderate disability and 23 per cent were severely disabled. The severe disablements included cerebral palsy, blindness, severe hearing loss and intellectual handicap. A number of babies had multiple disabilities. An important finding was that the incidence of disability increases with declining gestational age of the babies.

Johnson A, Townshend P, Yudkin $P$ et al. Functional abilities at age 4 years of children born before 29 weeks of gestation. $\mathrm{Br}$ Med J, 1993; 306:1715-1718.

\section{NEVER DISMISS WHAT A PATIENT TELLS YOU}

When a 90-year-old was admitted to hospital he asked the staff to let his mother know. The doctors thought he must be senile. In fact, his mother, at 113 years, is the oldest woman in Britain.

\section{Editorial. Br Med J, 1993; 307:48-49.}

\section{SEX, PREGNANCY, HORMONES AND MELANOMA}

Many questions remain unanswered about the relationship between melanoma (the most rapidly increasing Australian cancer) and the hormonal environment. Several conclusions can be made within the current state of knowledge. First, there is no evidence that the use of oestrogens, either as oral contraceptives or hormone replacement therapy, has a role in the aetiology of melanoma. Second, women have a survival advantage over men that could be due to the inhibitory effect of normal oestrogens in the growth of melanoma. Third, prescribed oestrogens do not promote progression of the disease in patients with melanoma, therefore women who have been treated for melanoma can safely use hormonal supplements. Last, pregnancy seems to carry no adverse effect on survival after treatment for melanoma. (However, patients with thick melanomic lesions are advised to delay pregnancy for two to three years as this is when they are at the greatest risk of relapse).

Jatoi I and Gore ME. Sex, pregnancy, hormones and melanoma. $\mathrm{Br} \mathrm{Med}$ $J, 1993 ; 307: 2-3$.

\section{BREAST-FEEDING REDUCES RISK OF BREAST CANCER}

A large British study has confirmed that breast-feeding is associated with a statistically significant decreased risk of breast cancer. The risk of breast cancer falls with increased duration of breast-feeding, and with the number of babies breast-fed. However, breast-feeding each baby for longer than three months confers no additional benefits.

United Kingdom National Case-Control Study Group. Breast feeding and risk of breast cancer in young women. $B r$ Med $J, 1993 ; 307: 17-20$. 